\title{
Erratum to: Carbon Capitalism and Communication
}

\author{
Benedetta Brevini and Graham Murdock
}

\section{Erratum to:}

B. Brevini and G. Murdock (eds.), Carbon Capitalism and Communication, Palgrave Studies in Media and Environmental Communication, https://doi.org/10.1007/978-3-319-57876-7

In the original version of the book, the credit line "cartoon courtesy of Tom Toles" was missing in the caption of Fig. III.l on page 109 and also in the List of Figures. The erratum book has been updated with the changes. 